\title{
LA SOCIOLOGÍA ANALIITICA ES UNA MAGNÍFICA OPCIÓN, PERO NO UNA PANACEA
}

\author{
Mariano Fernández Enguita \\ Universidad de Salamanca, España \\ enguita@usal.es
}

¿Necesita la sociología un giro analítico? ¿Resolvería esto sus problemas, o nos pondría al menos en la vía para hacerlo? Es difícil no perder los nervios, realmente, con lo que a veces pasa por sociología o con lo que desde otras disciplinas o desde la opinión publicada parece pensarse de ella. Lo que llena los estantes de sociología de las librerías, por desgracia, no es ya Bauman, como temen los autores del manifiesto, sino cosas mucho menos sociológicas. Una breve consulta a la sección en la web de la Casa del Libro, por ejemplo, nos devolverá la mención de obras como Mi marido me pega lo normal y Un burka por amor o un folleto publicitario sobre 25 años de autonomía en Castilla-La Mancha. La oferta de El Corte Inglés es bastante más razonable, pero la de Barnes and Noble es demencial y la de Amazon ni siquiera existe, y eso que allá la sociología está más y mejor establecida. Mientras tanto, los comentaristas de radio y televisión definen como un fenómeno sociológico cualquier cosa que llame la atención pero no parezca obedecer a racionalidad alguna, y algún que otro programa saca su particular sociólogo de la nada o se dedica a pulsar la opinión pública asaltando micrófono en mano a los viandantes que se dejen.

En estas circunstancias, un llamamiento al rigor, la claridad argumental, el debate en profundidad o la precisión conceptual no puede ser sino bien recibido. No creo que el panorama de la disciplina sea tan extremamente penoso, ni por dentro ni por fuera, como lo pintan los autores del Manifiesto, pues olvidan señalar rasgos como la proliferación (para bien y para mal, eso es cierto) de títulos y facultades, las multiplicación y consolidación de las revistas de impacto, la salida sistemática de los jóvenes investigadores a formarse en universidades extranjeras, el aumento de las publicaciones por cabeza, etc.; pero es cierto que, entre el buen trabajo de un número no desdeñable de buenos sociólogos y la verborrea opiniática generalizada propia de este país de tertulianos, en el que todo el mundo se atreve a hablar de todo en calidad de experto, hay toda una larga cola de sociología trivial, para la ocasión, alimentada a veces desde la propia profesión, incluidos el mundo académico y sus aliados. Por consiguiente, cualquiera que, siendo parte del primer grupo y no del segundo, lea los ocho principios formulados por los autores, es probable que esté básicamente de acuerdo en ellos. Pero el problema es precisamente ése, que la apuesta por la precisión, el rigor, la atención al lenguaje, la racionalidad epistémica, la explicación causal, la solidez teórica o la atención a otras ciencias no 
es ni puede ser exclusiva de ningún giro ni orientación determinados, sino que puede y debe ser más bien un impulso compartido por esta disciplina y esta profesión, como por cualesquiera otras. De hecho, entre los ocho principios señalados apenas hay dos, el quinto y el séptimo, que puedan considerarse específicos de una orientación o giro analíticos: el recurso a mecanismos y microfundamentos (que, por otra parte, no son la única manera de aproximarse a la causalidad) y la formalización (más aún si es modelización o matematización).

Estos son precisamente los que yo veo con mayor simpatía, pero, al mismo tiempo, no creo que por sí mismos garanticen nada a la sociología en su conjunto. En una parte considerable de mis trabajos he querido recurrir a los microfundamentos y a la modelización, incluida la modelización matemática, concretamente diversos trabajos publicados, y algunos otros inéditos, sobre los modos de producción, la explotación, las clases sociales o la discriminación. En otros casos no he llegado a los microfundamentos ni a la modelización pero sí a una pretensión de calidad conceptual (tal vez fallida, por qué no), aunque quizá no fuera otra cosa que rigor gráfico (lo que G. Hodgson atribuía irónicamente a E.O. Wright, uno de los referentes de los autores del llamamiento), por ejemplo al tratar del rechazo escolar, las desigualdades ante la educación, la sociología de las organizaciones, la sociedad de conocimiento, los centros escolares o los modelos profesionales). Pero, con sinceridad, no creo ni que estas formas analíticas y expositivas puedan extenderse por igual a todas las facetas de la realidad social ni que impliquen por sí mismas un mayor acercamiento a la verdad. Si tomamos, por ejemplo, la obra de Marx y Weber, sus análisis de las clases sociales podrían considerarse precursores de la sociología analítica a la vez que particularmente desafortunados. La obsesión de Marx por los microfundamentos, los mecanismos y la matematización (bien elemental, claro es, pero la modelización raramente necesita ser compleja) no sólo no le libró del peor reduccionismo, sino que pudo poner aquellos al servicio incondicional de éste. $Y$ la minuciosidad taxonómica de Weber a la hora de distinguir clases y clases sociales, propietarias y lucrativas, clases, estamentos y comunidades, etc. no le salvo de dejar un legado, en este ámbito, prácticamente estéril, si descontamos su sensata y acertada afirmación del carácter multidimensional de la desigualdad, el concepto algo desconectado de clausura y el tan manoseado como confuso de las oportunidades vitales. Por el contrario, la intuición marxiana sobre el papel de la lucha de clases (o de los intereses colectivos) en la historia o su lectura de las alineaciones de los actores colectivos en los conflictos francés, alemán o español, lo mismo que las interpretaciones weberianas de la racionalización de la vida social y de la relación entre religión y economía, que fueron todas ellas cualquier cosa menos analíticas, no han dejado por ello de quedar entre sus mejores aportaciones al estudio de la sociedad. Si se quiere un ejemplo más cercano, piénsese en la tan sugestiva y ben trovata como inútil reconstrucción del materialismo histórico de E.O. Wright (su reformulación de la secuencia feudalismo-capitalismosocialismo-comunismo-sociedad sin clases) o sus equilibrios en torno a los más que confusos conceptos de bienes de organización y bienes de cualificación a partir del trabajo de J. Roemer. 
Bienvenida sea, pues, y larga vida tenga la apuesta por el uso de los instrumentos y la adopción de un enfoque analítico en la sociología, pues son necesario, ciertos avances teóricos y conceptuales los incentivan y el desarrollo de las técnicas de investigación puede dotarlos de nuevos fundamentos. Evitemos, sin embargo, la ilusión de creer que lo que es posible en ciertos ámbitos puede extenderse al conjunto de la sociedad y de la sociología. La sociedad es demasiado compleja, y la aceleración del cambio social la lleva a serlo mucho más, mientras que la perspectiva analítica implica siempre una reducción consciente de esa complejidad; reducción que resulta útil y propedéutica en cuanto que permite arrojar luz sobre ciertos procesos y mecanismos, pero siempre al precio de dejar otros fuera. Cualquiera que sea el juicio que me merezcan cada uno de ellos o cada una de sus teorías y obras, me resulta difícil -por decirlo suavementeimaginar que el elenco de los sociólogos en quienes los autores ven representados los males de la sociología actual, entre los cuales Giddens, Beck, Bauman y Bourdieu de forma explícita, y Luhmann y Castells de manera implícita, pueda ser sustituido por la plantilla de la tan pretenciosa como exigua y mortecina European Academy of Sociology. 